\title{
Jean Pierre Lion, Le comte Joseph de Primoli et les Lettres françaises
}

\section{Maria Emanuela Raffi}

\section{Q OpenEdition}

1 Journals

\section{Edizione digitale}

URL: http://journals.openedition.org/studifrancesi/6072

DOI: 10.4000/studifrancesi.6072

ISSN: 2421-5856

\section{Editore}

Rosenberg \& Sellier

\section{Edizione cartacea}

Data di pubblicazione: 1 mai 2011

Paginazione: 206

ISSN: 0039-2944

\section{Notizia bibliografica digitale}

Maria Emanuela Raffi, «Jean Pierre Lion, Le comte Joseph de Primoli et les Lettres françaises», Studi Francesi [Online], 163 (LV | I) | 2011, online dal 30 novembre 2015, consultato il 13 janvier 2021. URL: http://journals.openedition.org/studifrancesi/6072 ; DOI: https://doi.org/10.4000/studifrancesi.6072

Questo documento è stato generato automaticamente il 13 janvier 2021.

\section{(c) (i) (9)}

Studi Francesi è distribuita con Licenza Creative Commons Attribuzione - Non commerciale - Non opere derivate 4.0 Internazionale. 


\title{
Jean Pierre Lion, Le comte Joseph de Primoli et les Lettres françaises
}

\author{
Maria Emanuela Raffi
}

\section{NOTIZIA}

JEAN PIERRE LION, Le comte Joseph de Primoli et les Lettres françaises, «Histoires littéraires», avril-mai-juin 2010, col. XI, n. 42, pp. 5-61.

1 Il lungo saggio di Jean Pierre Lion, arricchito dalla riproduzione di numerose fotografie e di lettere inedite, costituisce indubbiamente uno strumento prezioso per entrare con un'angolatura particolarissima nel mondo letterario francese, o franco-italiano, degli ultimi decenni del xIX secolo e dei primi del secolo successivo, seguendo la biografia e la multiforme attività del conte Joseph Primoli, figlio di Pietro Primoli e di Charlotte Bonaparte. Condotta sui documenti conservati alla Fondazione Primoli di Roma, la ricerca di Lion mostra gli spostamenti della famiglia fra Roma e Parigi, i numerosi viaggi e le importanti relazioni letterarie di Primoli nate in buona parte nel salotto della zia, principessa Mathilde, nipote di Napoleone I: Flaubert, i Goncourt, Daudet, Debussy e molti altri, oltre ad alcune amicizie personali come quella con Théophile Gautier, Maupassant e Alexandre Dumas fils. Sommate a quelle francesi, le amicizie italiane di Primoli, egualmente importanti e numerose - Verga, Pirandello e soprattutto D'Annunzio - gli consentirono di svolgere «des fonctions d'ambassadeur culturel entre la France et l'Italie» e di far pubblicare, ad esempio, dei testi di Matilde Serao a Parigi, nonché di raccogliere un grande numero di documenti autografi, ai quali nel 1904 si aggiunse la consistente eredità di lettere e testi di Mathilde Bonaparte. 